\title{
A Trickster approach to Interaction Design Isao Hosoe
}

"Indeed, since the book was published, a whole academic field has grown up around the idea of "design methods" - and I have been hailed as one of the leading exponents of these so called design methods. I am very sorry that this has happened, and

Want to state, publicly, that I reject the whole idea of design methods as a subject of study, since I think it is absurd to separate the study of designing from the practice of design. In fact, people who study design methods without also practicing design are almost always frustrated designers who have no sap in them, who have lost, or never had, the urge to shape things. Such a person will never be able to say anything sensible about "how" to shape things either"1.

Trickster: We live in an era of late positivism. Our historical phase is dominated by the supremacy of science. According to Comte, each branch of our knowledge passes successively through three different stages: theological (religious), metaphysical, (philosophical) and physical (scientific). The first stage is the necessary point of departure of intelligence; the second only represents the transition while the third stage is the stable, definitive one. In this rigorously linear and mono directional hypothesis our industrial society find it very difficult to determine new goals. In a circular hypothesis which is much closer to Eastern philosophy, the point of arrival could also be the point of departure. Having gone through science, we could anew direct ourselves toward a theological stage and research on the intimate nature of beings. Our culture, especially design culture, would be enriched by this unforeseen, dynamic hypothesis. The issue thus involves the determination of who shall guide this path change. The designer is particularly appropriate because he speaks two languages: the technological language of central power and the dialect of the periphery. The only language which science speaks is mathematic, the linear and digital language. The human world, where design is located, is made of unforeseeable things speaks an impure language. Not everyone knows how to move between these two worlds and understand their two languages; design can do it if it assumes the role of the trickster. Masao Yamaguchi ${ }^{2}$ elaborated an hypothesis on the cultural role of the trickster as a dynamic catalyst within the binominal center and periphery. Norms-scientific power-requires anomaly, madness, discontinuity because these elements introduce the concept of flexibility which allows the norm to adapt and to evolve. Therefore, the Trickster, instead of presenting a threat to the center it is a survival requirement; his messages contain a vital communication which is able to ensure the balance of the system. In any kind of society, absolute homogeneity can endanger social integration itself instead of guaranteeing it.

What has to come into play is the knowledge that anomalies are the productive element of our current society. How will the designer/ Trickster act in the interaction design? We cannot know this! The Trickster is very quick and unpredictable and he moves in away, which is surprising and not always follows the program. He can be

\footnotetext{
${ }^{1}$ Notes on the Synthesis of Form (1964), preface to the paper back edition (1971) by Christopher Alexander

${ }^{2}$ See Ref.
} 
invisible and transform himself but in any event he enjoys himself by means of short -lived appearances. He can only be seen at a glance and always in different garb.

Design common sense: In 1987 I had occasions to make interviews to two eminent persons from ergonomics; Prof. Etienne Grandjean and Prof. Sebastiano Bagnara. These interviews have been promoted by Ufficiostile ${ }^{3}$ and the editor chose me as the interviewer because I declared one year before on the pages of the same magazine: Ergonomics is not a science but a design common sense. My declaration provocated both consensus and dissensus. The editors intention has been to re-open the case throughout the interviews. May we invite you to follow some interesting parts of our interview?

Isao Hosoe: What kind of research methods do you use in ergonomics? Do you think that the laboratory science utilized mainly in the natural science in virtue of their reversibility and repetitively can be considered adaptable for ergonomics? Don't you think that the ergonomics to study the living human beings need new tools?

Etienne Grandjean: Actually in our institute, scientific tool like the questionnaires are used to obtain the information including the subjective sensations and emotions of the users. I don't think that the ergonomics is the laboratory science even if it has been so in the past, now more than half of our research work can be defined as the field science. The laboratory science has the advantage to have the constant parameters to be repeated while in the field science it is hard to rely on the constancy of the circumstances of the research work however field science gives us the opportunity to discover some important phenomena which could not be foreseen before.

I.H.: I think that one of the principal problems regarding the field science, above the questions relative to the adequacy of the tools of measurement, stays in the fact that the person who observes may influence the behavior of the observed and the real conditions of the environment examined.

E.G.: This kind of critic can be seen very often from the persons who prefer the laboratory method. We adopt several expedients, which may guarantee the validity of the research work. First of all we work on a big quantity of people so as to compensate the different reactions induced by the interferences provocated by the single observer in relation to a hundreds of people observed. It is also possible to distribute the questionnaire without any interference of the observer. Personally I prefer the individual meeting...

I.H.: I understand that you are well known to be considered the father of ergonomics and in contact every day with young ergonomists in the world, what is your opinion about their scientific level? Are you satisfied in the global scientific talent of the researchers of this field?

E.G.: It depends on the university where they come from. The situation is so pluralistic that it is very difficult to give any judgment on this argument. In some countries, the ergonomics is equivalent to the psychology then I believe that it is necessary in this case they need deeper study in physiology. In our case

(ETH Zurich) my successor is a computer-man so for my opinion he needs probably more notions in psychology. For me the ergonomics is

\footnotetext{
${ }^{3}$ Sias Renata, ed., Ergonomia nell'ufficio computerizzato. Isao Hosoe intervista E. Grandjean e S. Bagnara. In Uffiostile, Speciale Ergonomia, pp.14-23, n.6/7, 1987
} 
an interdisciplinary science and it is necessary to try to discover and investigate the new fields. When in one country a new frontier opens then other countries follow the examples. There will be always a new ergonomics which I'm sure does not come from the laboratories.

During the interview, Etienne Grandjean has talked about the new area of the ergonomics-the ergonomics of software-and the specific study on this argument which raises particular problematic regarding the psychological order. He remembered Sebastiano Bagnara as one of the most eminent researchers in this field.

Isao Hosoe: Today's culture is characterized by the changing attention from hardware to software. The ergonomics as it is conceived until today became old. The pathway that your research work is following is very interesting because it denotes the changing demands of the ergonomics.

Sebastiano Bagnara: I worked successively in three Fields. The first regards the hemispheric specialization and the performances of one and the other hemisphere for eminently visual task. Then I worked on the attention.

Now I'm studying about the error experimentally.

I.H.: Does the optimization as the basic criteria of the ergonomic intervention derive from the economy in the quantitative sense? And in consequence are the instruments used for these research quantitative rather than qualitative?

S.B.: No, not only. I show you one example. To study the simple mental process, I can use the mental chronometry methods to measure the time of execution and the quantity of errors done.

But if I put the problem of the modality of control, which the man has on his action and how he improves his control performance, then I have to use the qualitative method as the analysis of the verbal protocol. The behavioral descriptions are not necessarily obtained by the quantitative methods.

I.H.: The laboratory science needs as basic condition the reversibility and repeatability of the object. Unfortunately the human beings are for many aspects irreversible and unrepeatable, how can you resolve this basic contradiction in order that the laboratory research is valid.

S.B.: You have to know that very often the human behaviors are more than you image repeatable and so the statistic instruments can identify the constants respect to the variability.

In the laboratory the principal objective is not to describe aspects, which describes the peculiarity of single individual but to know the constants characterizing the general behavior.

I.H.: Is the ergonomics the interdisciplinary science, or the design commonsense?

S.B.: Being interdisciplinary sounds so static; means the application on one object from the different competences. The logic of design instead is something

Very different: the conquest and the interaction of different view points, the discovery of new things.

Abduction: In one of his Harvard Lectures delivered on April 1903 Charles Sanders Peirce gave us the idea of three human inferences; "These three kinds of reasoning are Abduction, Induction, and Deduction.

Deduction is the only necessary reasoning. It is the reasoning of mathematics. It starts from the hypothesis, the truth or falsity of 
which has nothing to do with the reasoning; and of course its conclusions are equally ideal the ordinary use of

the doctrine of chances is necessary reasoning, although it is reasoning concerning probabilities. Induction is the experimental testing of a theory. The justification of it is that, although the conclusion at any stage of the investigation may be more or less erroneous, yet the further application of the same method must correct the error.

The only thing that induction accomplishes is to determine the value of a quantity It sets out with a theory and it measures the degree of concordance of that theory with fact. It never can originate any idea whatever. No more can deduction. All the idea of science comes to it by the way of abduction. Abduction consists in studying facts and devising a theory to explain them.

Its only justification is that if we are ever to understand things at all, it must be in that way. ${ }^{\prime \prime}$

Massimo A. Bonfantini and Gianpaolo Proni ${ }^{5}$ in 1980 tried to abduct the Peircian Abduction defining it in three types:

First type of abduction- the applicable mediations law for inferring a case from a result is mandatory and automatic or semiautomatic;

Second type of abduction- the applicable mediation law for inferring a case from a result is sought by selection from the available encyclopedia;

Third type of abduction is the applicable mediation law for inferring a case from a result is constituted ex novo, invented.

Now I'd like to show you my abduction to the abduction already done by Bonfantini and Proni to the abduction of Peirce.

First abduction is Play: we are thinking of play not the game. Play needs a certain rule to keep and begin playing.

Your play performance becomes faster as your familiarity to the play grows up. Very often you make a mistake and that mistake gives you an idea you could not even imagine. Masao Yamaguchi in his introduction of the Japanese translation of THE TRICKSTER by Radin, Kerènyi and Jung points out the possible connection between the concept of play described in HOMO LUDENS by Johan Huizinga and trickster who never stop to play.

Movement sustains play and the movement needs the vacancy as sustained by Laotsu who has been considered the philosopher of the fluidity and in the same way Confucius may be defined as the philosopher of the solidity or of the power.

It is also interesting that Henri Bergson considered as philosopher of human beings as living entity says in the introduction of his "Creative Evolution" "We shall see that the human intellect feels at home among inanimate objects, more especially among solids, where our action finds its fulcrum and our industry finds its tools; that our concepts have been formed on the model of solids; that our logic is pre-

\footnotetext{
${ }^{4}$ AA.VV. The essential Peirce. Selected Philosophical Writings, Indiana University Press, Bloomington and Indianapolis, 1998, p.205

${ }^{5}$ See Ref.
} 
eminently the logic of solids; that, consequently, our intellect triumphs in geometry..."

Second abduction is Bricoleur: bricoleur is who makes the bricolage. The bricoleur comes from LA PENSEE SAUVAGE by Claude Lévi Strauss. Bricoleur with strong curiosity and excellent body enters in the forest where he can find any kind of existing things. He doesn't invent but gather things which stimulate his curiosity. In the evening he comes back to his house with the bag full of things gathered in the forest. He empties the bag out on the big table and he recognizes that among the things he gathered very few but highly interesting combinations he has never hoped to see.

Third abduction is Folly: folly means out of norm, out of average, out of standard, and out of dogma accepted by the people and sustained by the normality. Folly of Erasmus speaks: "Whatever is generally said of me by mortal men, and I'm quite well aware that Folly is in poor repute even amongst the greatest fools, still, I am the one an indeed, the only one- whose divine powers can gladden the hearts of gods and men." It is interesting to note that Erasmus says gods and men not god and men. It is clear that in his mind there were a lot of Greek generous gods rather than the exclusive monotheistic god. Erasmus intention in writing (The praise of folly 1511) seems to be his criticism against the monotheistic culture, which puts the heavy limits on human intellectual activities. A half millennium after Erasmus, Michel Foucault revealed that Erasmus was right in his (The history of folly 1961) where Foucault tells us how the monotheistic culture or the modernity tried to exclude the any presence of the diversity which is the mother of human creativity Abduction differs from Induction and Deduction because while the later two are based on the logic of continuity and reversibility, Abduction may not follow neither the logical continuity nor the reversibility. Abduction is the human inference, which is based on the nonlinear and irreversible logical structure. Abduction is like the dragon, which is considered as the creative divinity of the Indus river who suddenly jumps up to the sky and comes back when he likes. The dragon plays the role of communicator of two different worlds the ground and the sky. Abduction is like a fisherman who is able to know where the fishes live even if the water is turbid. Abduction is like a shaman hunter of the Siberian tundra who without any arms let the animals gathers with pleasure to be captured by the hunter.

Eight Senses: The page distribution of a 1000 page handbook for senses and perceptions gives us the idea of the dominant position of visual sense with 700 pages followed by the sense of hearing with 120 pages, the tactile sense with 60 pages, the sense of taste and the sense of smell with 40 pages respectively. The rest of the pages are dedicated for the sense of equilibrium and the sense of time with 20 pages each. The fact that the seventy per cent of the handbook pages are occupied by the visual sense is worthy for a deeper reasoning. Aristotle starts his monumental METAPHYSICS with the following: "ALL men by nature desire to know. An indication of this is the delight we take in our senses; for even apart from their usefulness they are loved for themselves; and above all others the sense of sight. For not

\footnotetext{
${ }^{6}$ Bergson, Henry, L'èvolution crèatrice, Presses Universitaires de France, Paris, 1941, p. V

Rotterdam, Erasmo Da, Elogio della follia, Mursia, Milano, 1966
} 
only with a view to action, but even when we are not going to do anything, we prefer seeing (one might say) to everything else. The reason is that this, most of all the senses, makes us know and brings to light many differences between things. "18

"To light many differences between things" brings directly to the scientific paradigm on which the western modernity has been constructed. Aristotle taught us to concentrate the attention on the visual sense. We may say that the western culture is fundamentally based on the visual sense.

Kukai $^{9}$ (774-835) is a Japanese monk who has succeeded the Esoteric Buddhism Shingon in the early 800 AD directly from Chinese Keika began the theological and philosophical construction of Shingon(mantra) teaching.

One of the monumental works completed by Kukai regarding the structure of Shingon universe is called (JUJUSHINRON) ${ }^{10}$ where we find a quite significative part describing the quality of water for Shingon Paradise.

Shingon Buddism knew that Aristotle's postulate on the sense of sight was limited and through the Esoteric teaching tried to "see" the part that was invisible. Kukai in his description of the universe touched in every detail in an exhaustive way, and it was precisely when he spoke about the qualities of water that he said there were 8 characteristics which guaranteed its excellence: it must be sweet, cool, soft, light, pure, odorless, pleasant to the throat, and does not hurt the stomach. In his description the sense of sight clearly plays a secondary role.

Aristotle, on the other hand, quotes Tales in a hasty way referring to the importance of water in so much as it is an essential quality for life, deducing this only from the fact the seeds have a moistly nature.

(The senses considered as perceptual systems 1966 by James J. Gibson) starts his introduction demanding, "What are the senses? It has always been assumed that the senses were channel of sensation. To consider them as systems for perception, as this proposes to do, may sound strange. But the fact is that there are two different meanings of the verb to sense, first, to detect something, and second, to have a sensation. When the senses are considered as perceptual systems the first meaning of the term is being used.

In the second meaning of the term there is the vast difference between sensations and perceptions..."

Now let me talk about "YUISHIKI"11 definable as Buddism psychology or better as the Depth Psychology of Buddism. Yuishiki is composed of eight senses, eye-sense, ear-sense, nose-sense, tongue-sense, bodysense, consciousness, mana-sense, alaya-sense where Freudian psychology stops at the unconsciousness as sixth sense and Jungian psychology adds the collective unconsciousness as seventh sense.

The consciousness for Yuishiki is considered as sixth sense after the five senses that we believe to know. Anyhow, most of the information's enter through the five senses filtered and controlled by

\footnotetext{
${ }^{8}$ Aristotele, La Metafisica, Unione Tipografico - Editrice Torinese, Torino, 1974

9 See Ref.

${ }^{10}$ See Ref.

${ }^{11}$ See Ref.
} 
the consciousness our sixth sense. These six senses belong to the area, which we pretend to understand.

Yuishiki says that beyond the sixth sense, a heart is hidden which is strictly attached to the EGO. This heart is the sense of Mana the seventh sense.

Mana in Sanskrit means, to measure, to doubt. In the depth of your heart you are always thinking about putting yourself your ego in the midst of your thought. When Descartes declared his well-known phrase "Cogito ergo sum", his mental background was the sense of mana of which center has been his Ego. If we go deeper in our sensorial world, we encounter the final sense called the sense of alaya the magazine of sense as Himalaya means the magazine of snow in Sanskrit. The sense of alaya includes all the memories which you have gathered during your life experiences through seven senses, what you have seen, what you have heard, what you have smelled, what you have tasted, what you have touched, what you have thought and what you have felt in your mind. Furthermore your sense of alaya does not include only your own memories but also it includes all the memories of your ancestress, which may cover hundreds, thousands, and million years time span. Most of the Buddhist practices as meditations, zazen, ablution, offer, service, talking about teaching etc. are considered as the mean to communicate with all eight senses. It is interesting to know that most of the knowledge that we believe to have can be reached exclusively through our practical experiences with the help of our eight senses.

Behavioral energy: "Behavioral energy" is the terminology coined by me some years ago preparing my workshops for several University Institutes and companies. The energy used by me in this context cannot be considered in KW or in HP instead may be understood with a certain degree of ambiguity as the original meaning "ACTIVITY" derived from both Latin Energia and Greek Energeia. I suppose that "activity" for Latin and for Greek has been considered as human activity however let me extend the term to all those activities not necessarily human but in the same time, which may reach the human perception through the eight senses, I described before.

Gibson's ${ }^{12}$ Affordance theory comes out in his (The ecological approach to visual perception, 1979) where he defines the field of his Affordance as follows; "I have described the environment as the surfaces that separate substances from the medium in which the animals live. But I have also described what the environment affords animals, mentioning the terrain, shelters, water, fire, objects, tools, other animals, and human displays".

Schematically the behavioral energy is contra posed to the material energy, in the same time both energies come out from the same ambient where we live.

To be clear in our context, the ambient we talk is where our interaction design concerns. Thinking of our civilization in which context we are speaking of the interaction design is to define even hypothetically the idea of our past, present and future. Roughly speaking, our old ancestress lived as nomad hunters for quarter million years, as farmers for a thousand years and in our industrial age for two hundred years. It seems that each time span diminishes so drastically that it is very hard to imagine what will be our

12 See Ref. 
successive age and how long it will last. However we may take it as granted that the event of the information technology has generated a different epoch even inside the industrial age. Let me call this epoch neomadic age as neonomadic as if the evolution of our civilization is cyclic or better spiral instead of linear type.

Consider that the time span dedicated for the nomadic hunter society is extremely long ( 250.000 years) compared to the last two civilizations (1.000 years for agricultural society and 200 years for industrial society). Just imagine how much memory is conserved in our eight senses especially in the last sense called the sense of alaya. I understand that in the course of the succession of different cultures many memories are destroyed, dispersed or just hidden. Many memories had to hide their selves for their future survival, many had transform their form to fit them to the time and they wait patiently because one day they will be appreciated in someway.

The possession is today considered one of the important human desires. But it is very easy to understand that the possession did not have a big importance in the precedent nomad hunters' society because except few things there was nothing to possess. Consumption is the very word created for the industrial society. It is true that consumption has been used even before the industrial age but the context in which the word has been used was circumscribed in a limited field. One is to consume the foods and the other is to consume the marriage. In both cases after the consumption nothing remains. Dedication is the right word for agriculture not only limited for farmers but also for all the life style of the people and the society sustained by agriculture. I believe that even the industrial society could start to grow up for their maturity thanks to the dedication of the workers who came from the agriculture. Agricultural dedication in the industrial society has been well sustained by the protestant dedication in Europe or by the Confucian dedication in Asia. Competition took place of dedication sooner when the capital system was aware of the market of which core function was the competition. The work as dedication/competition in the agricultural/industrial scenario may transform in the neomadic society scenario to the work as performance. As for the human senses, touch is for agriculture and sight is for industry while eight senses is for neomadic society. Regarding the human memory, the past memory is for agriculture, the present memory is for industry and the future memory is for neomadic society. Now let me talk about project as synonym of design. Project means to throw forward, to act for the future. Pro-ject means to perform on the future memory. The last word I'd like to mention in this culture comparison is time. The time for agriculture has been cyclic time while the industry preferred linear time. Fluid time is for neomadic society. In "The Dance of Life" (1983) Edward T. Hall speaking of the quality of time, he refers to the North European Monochronic time and South European or Indian Polychronic time says; "Particularly distressing to Americans is the way in which appointments are handled by polychronic people. Being on time simply doesn't mean the same thing as it does in the United States. Matters in a polychronic culture seem in a constant state of flux. Nothing is solid or firm, particularly plans for the future; even important plans may be changed right up to the minute of execution." Let's come back to the discussion on the behavioral energy and the material energy. Energy meant here activity, human activity or the 
result of the human activity meanwhile behavior means something which is able to communicate with human senses and material means something which is not able to communicate with human senses.

If the total amount of energy spent for something to be designed is constant, let's make effort to maximize the behavioral energy and to minimize the material energy. In another words, let's put more quality and intelligence in interaction design involving all the cultural matters and our eight senses and encouraging also the tacit dimensions above all our design common sense.

All this can be done in a manner that the transversal information transfer become the very common design tool and all who are involved in the Interaction Design become the Trickster who by nature moves everywhere capable to see things that common people don't see.

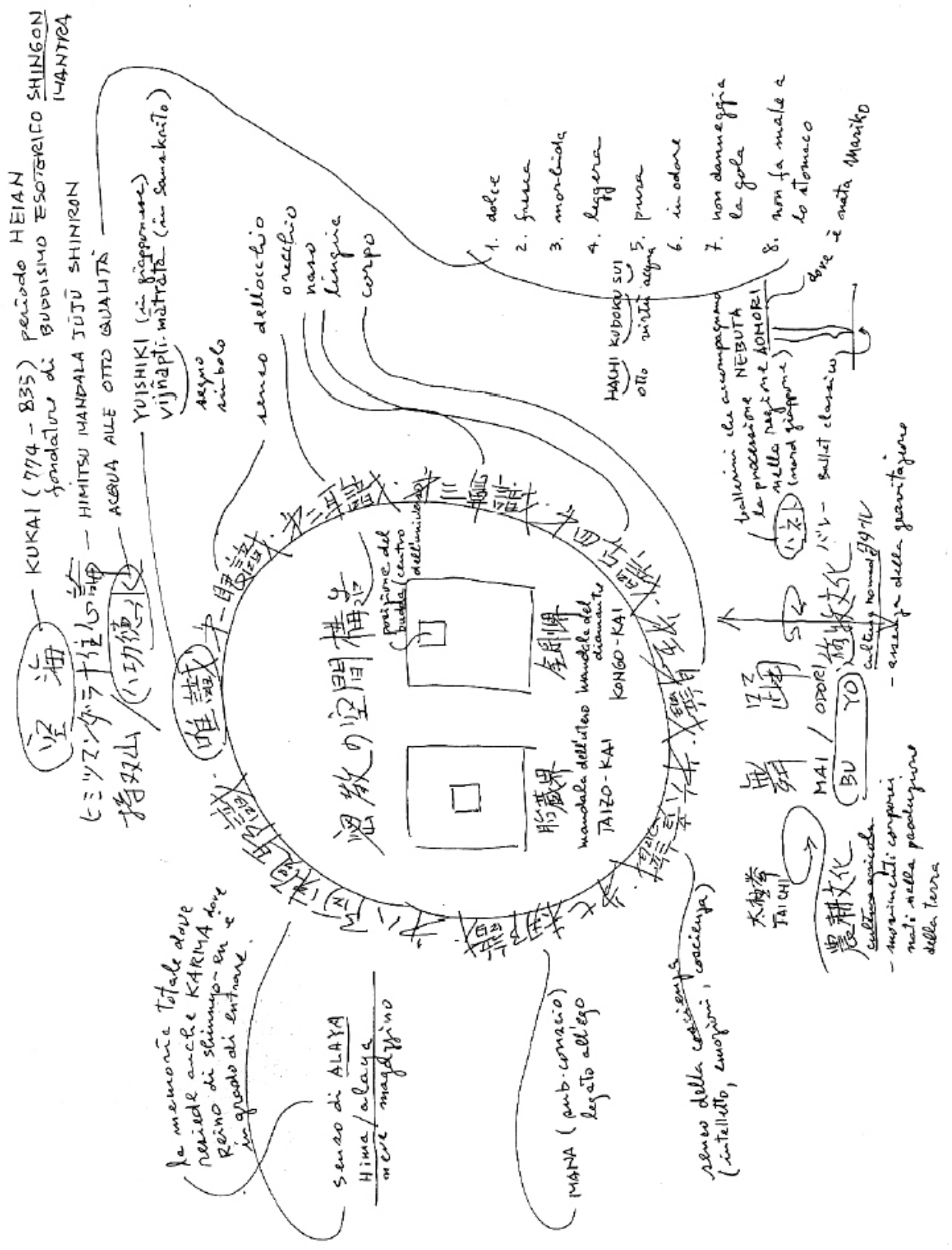


The cosmology of the depth psychology of Buddhism. The key to enter in the tacit dimension (drawn by Isao Hosoe) ${ }^{13}$

This text is written by Isao Hosoe in feb.2004, Milan

For the act to be published by Interaction Design Institute Ivrea SYMPOSIUM ON FOUNDATIONS OF INTERACTION DESIGN

November 12-13,2003, Ivrea -Italy

\section{References:}

Alexander, Christopher, Notes on the synthesis of form, Harvard Paperback, Cambridge, 1964

Aristotele, La Metafisica, Unione Tipografico - Editrice Torinese, Torino, 1974

AA.VV., The essential Peirce. Selected Philosophical Writings, Indiana University Press, Bloomington and Indianapolis, 1998

Bergson, Henry, L'èvolution crèatrice, Presses Universitaires de France, Paris, 1941

Bonfantini, Massimo A., La semiosi e l'abduzione, Bompiani, Milano, 1987

Bonfantini, Massimo A., Semiosis of Projectual Invention, in VS, Versus quaderni di studi semiotici, numero 55/56, Bompiani, Milano, 1990

De Rosa, Agostino, L'infinito svelato allo sguardo. Forme della rappresentazione estremo-orientale, Città Studi Edizioni, Torino, 1998

Gibson, James J., The senses considered as perceptual systems, Houghton Mifflin Company, Boston, 1966

Gibson, James J., The ecological approach to visual perception, LEA, London, 1986

Hall, Edward T., The dance of life. The other dimension of time, Anchor Press/Doubleday, New York, 1914

Huizinga, Johan, Homo Ludens, Einaudi, Torino, 1946

Yamaguchi, Masao, Culture and ambiguity, Iwa Nami Shoten, Tokyo, 1975

Yamaguchi, Masao, The poetics of culture, Iwa Nami Shoten, Tokyo, 1983

Yamaguchi, Masao, Culture and performance, Tsukuma Shobo, Tokyo, 1984

Yamaguchi, Masao, Trickster's world, Tsukuma Shobo, Tokyo, 1975

\footnotetext{
13 From the Afterword by Isao Hosoe in De Rosa, Agostino, L'infinito svelato allo sguardo. Forme della rappresentazione estremo-orientale, Città Studi Edizioni, Torino, 1998
} 
Kukai (Kobodaishi), Himitsu Mandala Jujushinron, First book, Tsukuma Shobo, Tokyo, 1983

Norman, Donald A., The psychology of everyday things, Basic Books Inc. Publishers, New York, 1988

Okano, Moriya, Yuishiki. Depth psychology of Buddism, Aotosha, Tokyo, 1990

Polanyi, Michael, Personal Knowledge. Towards a Post-Critical Philosophy, The University of Chicago Press, Chicago, 1958

Polanyi, Michael, The tacit dimension, Peter Smith, Gloucester, 1983 Rotterdam, Erasmo Da, Elogio della follia, Mursia, Milano, 1966

Sias, Renata, a cura di, Incontri di lavoro. Domesticità nell'ufficio, Edizioni Domus Academy, Milano, 1990 